\title{
Study of Path Analysis to Access the Direct and Indirect Effect of Yield Improving Components in Rice (Oryza sativa L.) under Sodic Soil
}

\author{
Akriti Dutt*, P. K. Singh and Soni Singh \\ Department of Genetics and Plant Breeding A. N.D.U.A \& T, \\ Kumarganj Ayodhya (U.P.), India \\ *Corresponding author
}

Keywords

Path Analysis, 1000 - grain weight \& Hybrid.

Article Info

Accepted: 05 February 2020 Available Online: 10 March 2020

\section{A B S T R A C T}

This research was conducted at main experiment station of A.N.D.U.A. \&T. Kumarganj, Ayodhya (U.P.) in rice growing season during 20152016.To determine the direct and indirect effect of yield improving component on yield improvement. The material consist of 21 hybrids (F1) developed through crossing 7 lines with 3 testers. Path analysis shows that harvest index, followed by spikelet fertility, biological yield per plant, panicle bearing tiller per plant and plant height are most important direct yield contributing component while harvest index followed by 1000- grain weight and spikelet fertility appeared as most important indirect yield components. These traits are considered at the time of devising selection strategy for developing high yielding varieties / hybrids in rice.

\section{Introduction}

Rice (Oryza sativa L., $2 \mathrm{n}=24$ ) belongs to the family Poaceae (Graminae). Rice has two cultivated and 22 wild species. The cultivated species are Oryza sativa and Oryza glaberrima. More than $90 \%$ of the world's rice is grown and consumed in Asia (Rice bowl of the world), where $16 \%$ of the earth's people and two third of world's poor live (Khush and Virk, 2000). Oryza sativa is grown in all over rice growing countries of the world, while Oryza glaberrima has been cultivated in west Africa for last 3504 years
(Anonymous, 2001). Rice is grown under different agro-climatic conditions and production systems but it is rated as an especially Salt-Sensitive Crop.

Rice is the only the cereal which can be grown successfully in standing water. It has been estimated that about 57 per cent of rice is grown on irrigated land; 25 per cent on rain fed low land; 10 per cent on the upland; 6 per cent in deep water and 2 per cent in tidal wet land. Paddy is a field of aquatic biodiversity, providing which many of them can be used as means to incorporate protein in to the diets of 
poor and malnourished people in low and middle income countries that farm rice (Anonymous, 2004). According to the forecast, the government of India revealed that 2015-2016 Kharif (June-December) rice production is around 90.6 million tons, which is slightly less from around 90.86 million tons of production in 2014-2015. Uttar Pradesh is an important rice growing state in the country. The area and production of rice in this state are about 5.98 million hectares and 14.63 million tonnes, respectively, with productivity of $2447 \mathrm{~kg}$ per hectares (Anonymous, 2014). Rice can be grown in many environments, so it has many characteristics making one variety more popular in one region of the world than another. The dominance of salt water across the surface of the earth has led to the widespread occurrence of salt affected soils and salt tolerant plants have evolved to grow on these soils.

Although, the information on above aspects in rice is available, but most of these studies are based on irrigated rice ecosystem and literature in context of stress environments such as sodic soil in rice is meager. Therefore, further studies aimed at generating and comparing information on above aspects in rice are warranted to facilitate development of high yielding rice varieties consisting good tolerance capacity for sodic soil conditions.

\section{Materials and Methods}

The basic material for the present investigation comprised of ten rice genotypes / varieties for seven lines viz., IR11T197, IR11T104, IR11T205, FL-478, pant basmati1, NDRK5009, IR 12 T193 and three testers viz.,CSR-10,CSR-36 and Jaya was obtained from various place were utilized for the study. The genotypes were used for crossing programme in a line $\mathrm{x}$ tester analysis ( 7 lines x 3 testers). Field plot was well prepared for sowing of experimental material (31 genotypes - comprising 10 parents and 21 $\mathrm{F}_{1} \mathrm{~s}$ seeds). Their of 10 parents and 1 check varieties (Narendra Usar 3 ) were evaluated in Randomized Complete Block Design with three replications during Kharif, 2016 at (M.ES of A.N.D.U.A\&T, Kumarganj Ayodhya).

The seeds of each entry were sown on $22^{\text {st }}$ June, 2016 in separate plots and 22 days $\left(14^{\text {th }}\right.$ July 2016) old seedlings were transplanted single seedling per hill in single row plots of 3 $m$ length with inter- and intra- row spacing of $20 \mathrm{~cm}$ and $15 \mathrm{~cm}$, respectively. All the recommended cultural practices were followed to raise a good crop. The observations were recorded on five randomly selected competitive plants of a genotype in a plot in each replication for twelve characters.

The mean values of observations recorded on five plants of each plot were used for analysis. Observation were recorded on days to 50 per cent flowering, plant height, panicle bearing tillers per plant, panicle length, flag leaf area, spikelet's per panicle, spikelet fertility, 1000grain weight, biological yield per plant, harvest-index and grain yield per plant. Path coefficient analysis was carried out according to Dewey and Lu (1959). Seed yield was assumed to be dependent variable (effect) which is influenced by all the ten characters, the independent variables (causes), directly as well as indirectly through other characters. The variation in seed yield unexplained by the ten causes was presumed to be contributed by a residual factor $(\mathrm{x})$ which is uncorrelated with other factors.

$$
\begin{gathered}
r_{i j}=P_{i y}+\sum_{j=1}^{10} r_{i j} P_{i y} j \text { or } i=1,2 \ldots \ldots 10 \\
r_{i j}=\sum_{j=1}^{10} r_{i j} P_{i y} \text { f or } r_{i j}=1
\end{gathered}
$$


The above equations can be written in the form of matrix.

$$
[\mathrm{A}]_{10 \times 1}=[\mathrm{B}]_{10 \times 1}[\mathrm{C}]_{10 \times 1}
$$

Where,

A is column vector of correlations $r_{i y}$

$\mathrm{B}$ is the correlation matrix of $\mathrm{r}_{\mathrm{ij}}$ and

$\mathrm{C}$ is the column vector of direct effect, $\mathrm{P}_{\text {iy }}$

Residual factor was calculated as follows:

Where,

$$
\mathrm{P}_{\mathrm{xy}}=\sqrt{1-\mathrm{R}^{2}}
$$

$$
R^{2}=\sum_{j} P_{i y} r_{i j}
$$

The $r_{i j}$ i.e. $r_{1.2}$ to $r_{11.12}$ denote correlations between all possible combinations of independent characters and $\mathrm{P}_{1 \mathrm{y}}$ to $\mathrm{P}_{10 \mathrm{y}}$ denote direct effects of various characters on character $\mathrm{y}$.

$\mathrm{r}_{\mathrm{iy}}=$ Correlation coefficient between $\mathrm{i}^{\text {th }}$ and $\mathrm{y}$ characters.

$P_{i y}=$ Direct effect of $i^{\text {th }}$ character on $y$.

\section{Results and Discussion}

Path coefficient analysis is a tool to partition the observed correlation coefficient into direct and indirect effects of yield components on grain yield. Path analysis provides clearer picture of character associations for formulating efficient selection strategy. Path coefficient analysis differs from simple correlation in that it points out the causes and their relative importance, whereas, the later measures simply the mutual association ignoring the causation.

The concept of path coefficient was developed by Wright (1921) and technique was first used for plant selection by Dewey and $\mathrm{Lu}$ (1959).
Path analysis has emerged as a powerful and widely used technique for understanding the direct and indirect contributions of different characters to economic yield in crop plants so that the relative importance of various yield contributing characters can be assessed. The direct and indirect effects of ten characters on grain yield per plant computed using phenotypic correlations are presented in Table 01 .

The highest positive direct effect on grain yield per plant was exerted by harvest index (0.414), followed by spikelet fertility (0.290), biological yield per plant (0.262), panicle bearing tillers per plant (0.203) and plant height (0.144).

The substantial negative direct effects were exhibited by day to $50 \%$ flowering $(-0.223)$, 1000- grain weight $(-0.179)$ and spikelets per panicle (-0.115).

The direct effects of remaining two characters, namely, panicle length (-0.047) and flag leaf area (-0.000) were negligible. Harvest index exhibited high order of positive indirect effects on grain yield per plant via panicle bearing tillers per plant (0.103). In contrast, high order of negative indirect effect was extended on flag leaf area $(-0.120)$ by harvest index.

Spikelet fertility showed substantial positive indirect effects on grain yield per plant via 1000 - grain weight $(0.144)$, while days to $50 \%$ flowering (-0.098) had considerable negative indirect effects via flag leaf area ($0.110)$.

The remaining estimates of indirect effects in this analysis were too low to be considered important. The estimates of residual factors (0.6163) was quite high in this path analysis. 
Table.1 Estimates of phenotypic direct and indirect effects of 11 traits on yield per plant in rice

\begin{tabular}{|c|c|c|c|c|c|c|c|c|c|c|c|c|}
\hline S.No. & Traits & D50F & PH & PBTP & PL & FLA & SP & SF & GW & BYP & HI & GYP \\
\hline $\mathbf{1}$ & D50F & $\mathbf{- 0 . 2 2 3}$ & -0.070 & 0.065 & 0.020 & -0.110 & 0.071 & 0.075 & 0.090 & 0.076 & 0.026 & $\mathbf{- 0 . 3 6 1}$ \\
\hline $\mathbf{2}$ & PH & 0.045 & $\mathbf{0 . 1 4 4}$ & -0.015 & 0.021 & 0.066 & -0.026 & -0.020 & 0.031 & -0.015 & -0.005 & $\mathbf{- 0 . 0 5 6}$ \\
\hline $\mathbf{3}$ & PBTP & -0.059 & -0.021 & $\mathbf{0 . 2 0 3}$ & -0.020 & -0.006 & 0.098 & 0.049 & 0.067 & -0.028 & 0.050 & $\mathbf{0 . 2 7 9}$ \\
\hline $\mathbf{4}$ & PL & 0.004 & -0.007 & 0.004 & $\mathbf{- 0 . 0 4 7}$ & -0.021 & -0.005 & 0.000 & -0.016 & -0.014 & 0.009 & $\mathbf{- 0 . 1 1 1}$ \\
\hline $\mathbf{5}$ & FLA & -0.003 & -0.0003 & 0.000 & -0.000 & $\mathbf{- 0 . 0 0 0}$ & 0.000 & 0.000 & -0.000 & 0.000 & 0.000 & $\mathbf{- 0 . 2 5}$ \\
\hline $\mathbf{6}$ & SP & 0.037 & 0.020 & -0.056 & -0.014 & -0.002 & $\mathbf{- 0 . 1 1 5}$ & -0.026 & -0.060 & 0.027 & 0.027 & $\mathbf{- 0 . 1 6 5}$ \\
\hline $\mathbf{7}$ & SF & -0.098 & -0.040 & 0.071 & -0.004 & 0.024 & 0.067 & $\mathbf{0 . 2 9 0}$ & 0.144 & 0.098 & 0.005 & $\mathbf{0 . 3 7 7}$ \\
\hline $\mathbf{8}$ & GW & 0.072 & -0.038 & -0.059 & -0.062 & -0.051 & -0.094 & -0.088 & $\mathbf{- 0 . 1 7 9}$ & -0.000 & 0.028 & $\mathbf{0 . 0 1 1}$ \\
\hline $\mathbf{9}$ & BYP & -0.089 & -0.027 & -0.037 & 0.080 & -0.030 & -0.062 & 0.088 & 0.001 & $\mathbf{0 . 2 6 2}$ & 0.025 & $\mathbf{0 . 4 4 5}$ \\
\hline $\mathbf{1 0}$ & HI & $\mathbf{- 0 . 0 4 9}$ & $\mathbf{- 0 . 0 1 6}$ & $\mathbf{0 . 1 0 3}$ & $\mathbf{- 0 . 0 8 4}$ & $\mathbf{- 0 . 1 2 0}$ & $\mathbf{- 0 . 0 9 9}$ & $\mathbf{0 . 0 0 8}$ & $\mathbf{- 0 . 0 6 5}$ & $\mathbf{0 . 0 4 0}$ & $\mathbf{0 . 4 1 4}$ & $\mathbf{0 . 5 8 3}$ \\
\hline
\end{tabular}

Residual effect $=0.6163$, Direct effects on main diagonal (bold figures)

Traits: D50F $=$ Days to 50\% flowering, $\mathrm{PH}=$ Plant height, $\mathrm{PBTP}=$ Panicle bearing tillers plant $^{-1}, \mathrm{PL}=$ Panicle length $(\mathrm{cm}), \mathrm{FLA}=$ Flag leaf area $\left(\mathrm{cm}^{2}\right), \mathrm{SP}=$ Spikelet's per panicle, $\mathrm{SF}=$ Spikelet Fertility $(\%), \mathrm{GW}=$ Grain weight $(\mathrm{g}), \mathrm{BYP}=$ Biological yield plant ${ }^{-1}(\mathrm{~g}), \mathrm{HI}=$ Harvest index $(\%), \mathrm{GYP}=$ Grain yield per plant.

Table.2 Estimates of genotypic direct and indirect effects of 11 traits on yield /plant in rice

\begin{tabular}{|c|c|c|c|c|c|c|c|c|c|c|c|c|}
\hline Sr.No. & Traits & D50F & PH & PBTP & PL & FLA & SP & SF & GW & BYP & HI & GYP \\
\hline $\mathbf{1}$ & D50F & $\mathbf{- 0 . 2 7 6}$ & -0.090 & 0.085 & 0.029 & -0.136 & 0.093 & 0.096 & 0.120 & 0.101 & 0.041 & $\mathbf{- 0 . 3 8 4}$ \\
\hline $\mathbf{2}$ & pH & 0.059 & $\mathbf{0 . 1 8 1}$ & -0.018 & 0.029 & 0.088 & -0.033 & -0.026 & 0.041 & -0.019 & -0.010 & $\mathbf{- 0 . 0 6 5}$ \\
\hline $\mathbf{3}$ & PBTP & -0.055 & -0.018 & $\mathbf{0 . 1 7 9}$ & -0.018 & -0.003 & 0.095 & 0.045 & 0.070 & -0.024 & 0.065 & $\mathbf{0 . 3 2 3}$ \\
\hline $\mathbf{4}$ & PL & -0.002 & 0.004 & -0.002 & $\mathbf{0 . 0 2 5}$ & 0.011 & 0.003 & -0.000 & 0.009 & 0.007 & -0.007 & $\mathbf{- 0 . 1 2 5}$ \\
\hline $\mathbf{5}$ & FLA & 0.014 & 0.014 & -0.000 & 0.013 & $\mathbf{0 . 0 2 9}$ & 0.00 & 0.002 & 0.008 & -0.004 & -0.011 & $\mathbf{- 0 . 2 7 4}$ \\
\hline $\mathbf{6}$ & SP & 0.024 & 0.013 & -0.038 & -0.008 & -0.000 & $\mathbf{- 0 . 0 7 2}$ & -0.017 & -0.039 & 0.018 & 0.022 & $\mathbf{- 0 . 1 7 8}$ \\
\hline $\mathbf{7}$ & SF & -0.130 & -0.054 & 0.094 & -0.013 & 0.027 & 0.091 & $\mathbf{0 . 3 7 3}$ & 0.190 & 0.131 & 0.017 & $\mathbf{0 . 4 1 7}$ \\
\hline $\mathbf{8}$ & GW & 0.127 & -0.066 & -0.114 & -0.106 & -0.084 & -0.160 & -0.149 & $\mathbf{- 0 . 2 9 2}$ & 0.003 & 0.067 & $\mathbf{- 0 . 0 0 1}$ \\
\hline $\mathbf{9}$ & BYP & -0.075 & -0.022 & -0.028 & 0.062 & -0.029 & -0.052 & 0.072 & -0.002 & $\mathbf{0 . 2 0 5}$ & 0.017 & $\mathbf{0 . 4 5 7}$ \\
\hline $\mathbf{1 0}$ & HI & $\mathbf{- 0 . 0 7 0}$ & $\mathbf{- 0 . 0 2 7}$ & $\mathbf{0 . 1 6 7}$ & $\mathbf{- 0 . 1 3 8}$ & $\mathbf{- 0 . 1 7 6}$ & $\mathbf{- 0 . 1 4 2}$ & $\mathbf{0 . 0 2 1}$ & $\mathbf{- 0 . 1 0 6}$ & $\mathbf{0 . 0 3 8}$ & $\mathbf{0 . 4 6 3}$ & $\mathbf{0 . 6 6 5}$ \\
\hline
\end{tabular}

Residual effect $=0.5366$, Direct effects on main diagonal (bold figures)

Traits: D50F $=$ Days to $50 \%$ flowering, $\mathrm{PH}=$ Plant height, $\mathrm{PBTP}=$ Panicle bearing tillers plant $^{-1}, \mathrm{PL}=$ Panicle length $(\mathrm{cm})$, FLA $=$ Flag leaf area $\left(\mathrm{cm}^{2}\right), \mathrm{SP}=$ Spikelet's per panicle, $\mathrm{SF}=$ Spikelet Fertility $(\%), \mathrm{GW}=$ Grain weight $(\mathrm{g}), \mathrm{BYP}=$ Biological yield plant ${ }^{-1}(\mathrm{~g}), \mathrm{HI}=$ Harvest index $(\%), \mathrm{GYP}=$ Grain yield per plant.

The direct and indirect effects of 10 characters on grain yield per plant estimated by path coefficient analysis using genotypic correlations are given in Table 02. The highest positive direct effect on grain yield per plant was exerted by harvest index (0.463), followed by spikelet fertility (0.373), biological yield per plant (0.205), plant height $(0.181)$ and panicle bearing tillers per plant (0.179). The substantial negative direct effects on grain yield per plant were extended by spikelet fertility (-0.292) and day to $50 \%$ flowering (-0.276). The direct effects of remaining three characters were too low to be considered important.
Harvest index exhibited high order of positive indirect effects on grain yield per plant via panicle bearing tillers per plant (0.167). In contrast, high order of negative indirect effects were extended by 1000 - grain weight $(-0.106)$, panicle length $(-0.138)$, spikelet's per panicle $(-0.142)$, flag leaf area $(-0.176)$. Spikelet fertility exhibited high order of positive indirect effects on grain yield per plant via biological yield per plant (0.131), 1000- grain weight $(0.190)$, but it had considerable negative indirect effects on grain yield per plant via days to $50 \%$ flowering,(0.130 ). 
The 1000-grain weight recorded considerable indirect effects of positive nature on grain yield per plant via day to $50 \%$ flowering $(0.127)$ and negative nature via spikelet's per panicle (-0.160), spikelet fertility $(-0.149)$ and panicle bearing tillers per plant (-0.114). Days to $50 \%$ flowering had considerable positive indirect effects via 1000 -grain weight $(0.120)$ and biological yield per plant (0.101) and negative indirect effects via flag leaf area (0.136).

The rest of the estimates of indirect effects obtained in path analysis were negligible. The estimates of residual factors (0.5366) obtained in this path analysis was not much low. The very high positive direct effects on grain yield per plant were exerted by harvest index and followed by spikelet fertility, biological yield per plant, panicle bearing tillers per plant and plant height at phenotypic and genotypic level (Tables 1 and 2).

Thus, harvest index spikelet fertility, biological yield per plant, panicle bearing tillers per plant and plant height emerged as most important direct yield components on which emphasis should be given during simultaneous selection aimed at improving grain yield in rice. These characters have also been identified as major direct contributors towards grain yield by Jayasudha and Sharma (2010), Akhtar et al., (2011), Rangare et al., (2012) and Bhatia et al., (2013).

Days to $50 \%$ flowering, spikelet's per panicle and 1000-grain weight showed considerable negative direct effect on grain yield per plant at genotypic as well as phenotypic levels, which indicated that genotypes having moderate mean performance for these traits would be more conducive for higher grain yield production. Eradasappa et al., (2007), Babar et al., (2009), Jayasudha and Sharma (2010), Akhtar et al., (2011), Rangare et al., (2012) and Bhatia et al., (2013) have also identified above mentioned characters as important direct and indirect yield contributing characters.

Path analysis identified harvest index followed by spikelet fertility, biological yield per plant, panicle bearing tillers per plant and plant height as most important direct yield contributing traits and harvest index, followed by 1000-grain weight and spikelet fertility emerged as important indirect yield components. Thus, the above mentioned six traits merit due consideration at time of devising selection strategy aimed at developing high yielding varieties in rice for salt affected sodic soil conditions.

\section{References}

Anonymous (2001). Rice research and production in the $21^{\text {st }}$ century Garmene Refernce ID 8380.

Anonymous (2004). Souvenir: Rice production in U.P. key to food and nutritional security \& improvement of farmers live hood December 13-14.

Anonymous (2014). U.P. Directorate of Agricultural Statistics Reports.

Akhtar, N.; Nazir, M.F.; Rabnawaz, A.; Mahmood, T.; Safdar, M. E.; Asif, M. and Rehman, A. (2011).Estimation of heritability, correlation and path coefficient analysis in fine grain rice (Oryza sativa L.).The Journal of Animal \& Plant Sciences, 21(4):660-664.

Babar, M.; Khan, A.A.; Arif, A.; Zafar, Y. and Arif, M. (2009).Path analysis of some leaf and panicle traits affecting grain yield in double haploid lines of rice (Oryza sativa L.).J. Agric. Res., 45 (4): 245-252.

Bhatia, P.; Jain, R. K. and Chowdhury, V. K. (2013).Genetic variability, correlation and path coefficient analysis for grain yield and its components in rice (Oryza sativa L.). Annals of Biology, 29 (3):282-287. 
Dewey, D.R. and Lu, K.H. (1959). A correlation and path coefficient analysis of components of crested wheat grass seed production. Agron. J., 51: 515-518.

Eradasappa, E.; Ganapathy, K.N.; Satish, R.G.; Santhala, J. and Nandarajan, N. (2007). Heterosis studied for yield and yield components using CMS lines in rice. Crop Res., 34 (1, 2 \& 3): 152-155.

Jayasudha, S. and Sharma, D. (2010). Genetic parameters of variability, correlation and path-coefficient for grain yield and physiological traits in rice (Oryza sativa L.) under shallow lowland situation. Electronic Journal of Plant Breeding,
1(5): 1332-1338.

Khush, G.S. 1997. Origin, dispersal, cultivation and variation of rice. Plant Mol. Biol., 35:25-34.

Rangare, N.R.; Krupakar, A. ;Ravichandra, K.; Shukla, A.K. and Mishra, A.K. (2012). Estimation of characters association and direct and indirect effects of yield contributing traits on grain yield in exotic and Indian rice (Oryza sativa L.) germplasm. International Journal of Agri Science ,2(1):54-61.

Wright, S. (1921). Correlation and causation. J. Agric. Res., 203: 557-585.

\section{How to cite this article:}

Akriti Dutt, P. K. Singh and Soni Singh. 2020. Study of Path Analysis to Access the Direct and Indirect Effect of Yield Improving Components in Rice (Oryza sativa L.) under Sodic Soil. Int.J.Curr.Microbiol.App.Sci. 9(03): 631-636. doi: https://doi.org/10.20546/ijcmas.2020.903.075 